British Journal of Nutrition (2021), 125, 494-507

(C) The Author(s), 2020. Published by Cambridge University Press on behalf of The Nutrition Society. This is an Open Access article, distributed under the terms of the Creative Commons Attribution licence (http://creativecommons.org/licenses/by/4.0/), which permits unrestricted re-use, distribution, and reproduction in any medium, provided the original work is properly cited.

\title{
Supplemental Bacillus subtilis DSM 29784 and enzymes, alone or in combination, as alternatives for antibiotics to improve growth performance, digestive enzyme activity, anti-oxidative status, immune response and the intestinal barrier of broiler chickens
}

\author{
Yuanyuan Wang ${ }^{1}$, Chianning Heng ${ }^{1}$, Xihong Zhou ${ }^{2}$, Guangtian $\mathrm{CaO}^{3}$, Lei Jiang ${ }^{1}$, Jiangshui Wang ${ }^{1}$, \\ Kaixuan $\mathrm{Li}^{1}$, Dianchun Wang ${ }^{1}$ and Xiuan Zhan ${ }^{1 *}$ \\ ${ }^{1}$ College of Animal Sciences, Zhejiang University, Hangzhou, People's Republic of China \\ ${ }^{2}$ Institute of Subtropical Agriculture, Chinese Academy of Sciences, People's Republic of China \\ ${ }^{3}$ College of Standardisation, China Jiliang University, Hangzhou, People's Republic of China
}

(Submitted 3 December 2019 - Final revision received 12 June 2020 - Accepted 15 July 2020 - First published online 22 July 2020 )

\section{Abstract}

The present study investigated the effect of Bacillus subtilis DSM 29784 (Ba) and enzymes (xylanase and $\beta$-glucanases; Enz), alone or in combination (BE) as antibiotic replacements, on the growth performance, digestive enzyme activity, immune response and the intestinal barrier of broiler chickens. In total, 1200 1-d-old broilers were randomly assigned to five dietary treatments, each with six replicate pens of forty birds for $63 \mathrm{~d}$ as follows: (a) basal diet (control), supplemented with (b) $1 \times 10^{9}$ colony-forming units (cfu) $/ \mathrm{kg} \mathrm{Ba}$, (c) $300 \mathrm{mg} / \mathrm{kg} \mathrm{Enz}$, (d) $1 \times 10^{9} \mathrm{cfu} / \mathrm{kg} \mathrm{Ba}$ and $300 \mathrm{mg} / \mathrm{kg}$ Enz and (e) $250 \mathrm{mg} / \mathrm{kg}$ enramycin (ER). Ba, Enz and BE, similar to ER, decreased the feed conversion rate, maintained intestinal integrity with a higher villus height:crypt depth ratio and increased the numbers of goblet cells. The BE group exhibited higher expression of claudin- 1 and mucin 2 than the other four groups. BE supplementation significantly increased the $\alpha$-diversity and $\beta$-diversity of the intestinal microbiota and markedly enhanced lipase activity in the duodenal mucosa. Serum endotoxin was significantly decreased in the BE group. Compared with those in the control group, increased superoxide dismutase and glutathione peroxidase activities were observed in the jejunal mucosa of the $\mathrm{Ba}$ and $\mathrm{BE}$ groups, respectively. In conclusion, the results suggested that dietary treatment with Ba, Enz or BE has beneficial effects on growth performance and anti-oxidative capacity, and BE had better effects than Ba or Enz alone on digestive enzyme activity and the intestinal microbiota. Ba or Enz could be used as an alternative to antibiotics for broiler chickens.

Key words: Lingnan yellow broilers: Antibiotics: Bacillus subtilis DSM29784: Intestinal barrier: Anti-oxidative capacity: Immunity capacity

For more than 60 years, sub-therapeutic levels of dietary antibiotics have been used in the livestock and poultry industry to improve growth performance and prevent diseases ${ }^{(1,2)}$. Antibiotics stabilise the bacterial population present in the digestive tract resulting in improved performance and reduced morbidity and mortality due to clinical and subclinical diseases ${ }^{(3)}$. Enramycin (ER) is a large molecule polypeptide antibiotic effective against pathogens of the gut flora ${ }^{(4)}$ and exhibits a strong inhibitory effect against Clostridium perfringens ${ }^{(5)}$, the pathogen responsible for inducing necrotic enteritis in chickens ${ }^{(6)}$.

Although this has been beneficial for animal health and productivity, it has essentially been a double-edged sword as antibiotic resistance and antibiotic residues in animal products threaten human health ${ }^{(7)}$. In response to this situation, antibiotic usage as growth promoters in feed has been banned in the European Union and there is increasing pressure for stricter regulations in North America ${ }^{(8)}$. A ban on feed antibiotics will be implemented in China in 2020. However, limitation of antibiotics has led to problems such as reduction in animal performance and feed conversion, and an increased incidence of certain animal diseases ${ }^{(9,10)}$. Therefore, exploring alternatives to antibiotics is an urgent task. Researchers are focusing on alternatives to antibiotics to improve animal performance and optimise gut health ${ }^{(11)}$. These alternatives include acidifiers (organic acids), prebiotics, probiotics, enzymes, herbal products, microflora enhancers and immune modulators.

Abbreviations: Ba, Bacillus subtilis DSM 29784; BE, Bacillus subtilis DSM 29784 and enzymes combination; Enz, xylanase and $\beta$-glucanases; ER, enramycin; ET, endotoxin; GSH-Px, glutathione peroxidase; MUC-2, mucin 2; sIgA, secretory IgA; SOD, superoxide dismutase; T-AOC, total antioxidant capacity.

* Corresponding author: Xiuan Zhan, email xazan@zju.edu.cn 
The use of probiotics in broiler diets is a strategy that can improve diversity and stability of the intestinal microbiota, immunomodulation, competition for adhesion sites and the production of antimicrobial agents resulting in improved broiler performance ${ }^{(12-14)}$. In addition, accumulating studies indicate that probiotics exert beneficial effects on body anti-oxidative capacity, digestive enzymes and nutrient absorption and decrease cell apoptosis, which finally favours the gut health and production performance of broilers ${ }^{(15-18)}$. Among many bacterial species used as probiotics, spore-forming Bacillus spp. has been identified as a suitable probiotic owing to the resistance of its spores to harsh conditions and long-term storage at ambient temperature ${ }^{(19,20)}$. Bacillus subtilis is not a normal intestinal microorganism but rather is a facultative anaerobe that can grow in the gut ${ }^{(21)}$. Bacillus subtilis DSM 29784 (Ba) was originally isolated from soil and deposited in the Deutsche Sammlung von Mikroorganismen und Zellkulturen. Previous studies have demonstrated that $\mathrm{Ba}$ can improve growth performance and gut health in pullets ${ }^{(22)}$ and turkeys ${ }^{(23)}$. However, there is little experimental research on the effect of $\mathrm{Ba}$ on the antioxidant status, immune response and gut microbiota of broilers.

Currently, non-conventional feed ingredients, such as barley and by-products from biofuel industries and other agroindustries, are being used as an alternative feedstuff to reduce the cost of broiler feed production ${ }^{(24)}$. However, these feed ingredients are inherently high in non-starch polysaccharides. These non-starch polysaccharides produce an anti-nutritive effect by increasing viscosity and entrapping nutrients in digesta $^{(25)}$. Broilers lack endogenous enzymes required for non-starch polysaccharides digestion and thus exhibit reduced feed efficiency when fibre content is increased even in a nutritionally complete $\operatorname{diet}^{(26)}$. Supplemental xylanase and $\beta$-glucanase can disrupt the plant cell wall matrix by hydrolysing inaccessible carbohydrates ${ }^{(27)}$. Previous studies have documented that the use of xylanase and $\beta$-glucanase can partially hydrolyse non-starch polysaccharides, reduce the viscosity of gut contents and result in improved nutrient absorption ${ }^{(28)}$. Further, these enzymes could improve the growth performance and gut health, increase the villus size and villus height:crypt depth ratio and influence caecal microbiota ${ }^{(29,30)}$.

To the best of our knowledge, the combined use of exogenous digestive enzymes and probiotics as supplements in broilers has rarely been reported. However, combined supplementation of exogenous enzymes and probiotics could result in complementary modes of action. According to Adeoye et al. ${ }^{(31)}$, supplementation of the diet with a combination of enzymes and probiotics can improve gut health without deleterious effects on the intestinal microbial composition as probiotics have the ability to produce fibre-degrading enzymes that might complement endogenous enzyme activity. In addition, exogenous digestive enzymes could increase the availability of suitable substrates for the probiotic and improve the growth of other beneficial bacteria. Given the potential complementary modes of action of the exogenous digestive enzymes and probiotics, the two products could improve the growth performance and health status of broilers when fed diets supplemented with both enzymes (Enz treatment) and probiotics as a cocktail. Therefore, it was hypothesised that the combination of $\mathrm{Ba}$ and Enz (BE) might have a synergistic effect that could result in improved intestinal health and overall broiler performance. The present study aimed to assess the effectiveness of the $\mathrm{Ba}$ and Enz blend in comparison with that of ER on the growth performance, digestive enzyme activity, anti-oxidative status, immune response and the intestinal barrier of broiler chickens.

\section{Materials and methods}

\section{Probiotics and enzyme preparation}

The B. subtilis strain was originally isolated from soil and has not been GM. The strain has been deposited in the Deutsche Sammlung von Mikroorganismen und Zellkulturen with the accession no. DSM 29784. Ba was cultured on Luria-Bertani media, kept at $37^{\circ} \mathrm{C}$ for $24 \mathrm{~h}$ and shaken at $180 \mathrm{rpm}$. Pure bacterial cells were collected after centrifugation at $5000 \boldsymbol{g}$ for $10 \mathrm{~min}$ at $4^{\circ} \mathrm{C}$. Then, these cells were washed twice with sterile $0.85 \%$ sodium chloride solution. Ultimately, the culture purity and identification were constantly checked via the spread plate $\operatorname{method}^{(32)}$. The exogenous enzyme complex primarily contained $3200 \mathrm{U} / \mathrm{g} \beta$-glucanase and $6225 \mathrm{U} / \mathrm{g}$ xylanase. Xylanase and $\beta$-glucanase activities were determined as described by Cosson et al. ${ }^{(33)}$. The unit of activity was defined as the amount of enzyme that releases one micromole of reducing sugars per minute at a $\mathrm{pH}$ of $4-8$ and a temperature of $50^{\circ} \mathrm{C}$.

\section{Chickens, diet and management}

A total of 1200 1-d-old Lingnan yellow broilers were randomly allotted to a total of thirty floor pens (area of $2 \mathrm{~m} \times 4 \mathrm{~m}$ ) covered with fresh wood shavings, and the total weight of forty chicks (twenty males and twenty females) per pen was equivalent. The birds in five treatment groups each consisted of six replicates with forty chicks per replicate. The birds were allowed ad libitum access to water and diets throughout (days 1-63) and were kept under light-dark (2L-1D) cycles every day. The control group was fed the basal diet and the treatment groups received (a) the same basal diet supplemented with (b) $1 \times 10^{9}$ colony-forming units (cfu)/kg Ba powder, (c) $300 \mathrm{mg} / \mathrm{kg}$ Enz $(3200 \mathrm{U} / \mathrm{g} \quad \beta$-glucanase and $6225 \mathrm{U} / \mathrm{g}$ xylanase), (d) $1 \times 10^{9} \mathrm{cfu} / \mathrm{kg} \mathrm{Ba}$ powder and $300 \mathrm{mg} / \mathrm{kg}$ Enz and (e) $250 \mathrm{mg} / \mathrm{kg}$ ER, for $63 \mathrm{~d}$. The experimental diet was designed according to National Research Council requirements ${ }^{(34)}$. The composition and nutrient levels of the basal diets are shown in Table 1.

\section{Measurement of growth performance}

Feed intake and body weight were recorded on a per replicate basis on days 1, 21, 42 and 63. Mortality was checked daily, and dead birds were recorded and weighed to adjust estimates of gain, intake and feed conversion ratios, as appropriate. The average daily gain, average daily feed intake (ADFI) and feed: gain ratio (F:G) were calculated. At $63 \mathrm{~d}$ of age, birds were deprived of feed overnight and weighed immediately prior to slaughter. 
Table 1. Composition and nutrient level of the basal diet (\% as fed basis)

\begin{tabular}{|c|c|c|c|}
\hline Ingredients & $\begin{array}{l}\text { Starter } \\
(1-21 \mathrm{~d})\end{array}$ & $\begin{array}{l}\text { Grower } \\
(22-42 \text { d) }\end{array}$ & $\begin{array}{l}\text { Finisher } \\
(43-63 d)\end{array}$ \\
\hline Maize & $58 \cdot 00$ & $40 \cdot 00$ & $42 \cdot 00$ \\
\hline Sorghum & & $16 \cdot 00$ & $17 \cdot 00$ \\
\hline Barley & & $10 \cdot 00$ & 13.00 \\
\hline Broken rice & $5 \cdot 00$ & & \\
\hline Soyabean meal & $30 \cdot 50$ & $18 \cdot 00$ & $11 \cdot 00$ \\
\hline Maize gluten meal & $2 \cdot 00$ & $5 \cdot 00$ & $5 \cdot 00$ \\
\hline Distillers dried grains with solubles & & $5 \cdot 00$ & $5 \cdot 00$ \\
\hline Lard & & 2.00 & 3.00 \\
\hline Soyabean oil & 0.50 & & \\
\hline Salt & 0.14 & 0.11 & 0.10 \\
\hline Calcium hydrogen phosphate & $1 \cdot 20$ & 1.00 & 0.80 \\
\hline Limestone & 1.50 & $1 \cdot 20$ & $1 \cdot 20$ \\
\hline Zeolite & & 0.50 & 0.70 \\
\hline Premix ${ }^{*}$ & 1.00 & 1.00 & 1.00 \\
\hline Total & $100 \cdot 00$ & $100 \cdot 00$ & $100 \cdot 00$ \\
\hline $\mathrm{ME}(\mathrm{MJ} / \mathrm{kg}) \dagger$ & $12 \cdot 26$ & 12.59 & 12.97 \\
\hline Crude protein & 21.02 & $19 \cdot 06$ & $18 \cdot 20$ \\
\hline Lysine & 1.09 & 0.98 & 0.86 \\
\hline Methionine & 0.50 & 0.41 & 0.38 \\
\hline Methionine + cysteine & 0.87 & 0.73 & 0.66 \\
\hline $\mathrm{Ca}$ & 1.04 & 0.92 & 0.87 \\
\hline Total P & 0.69 & 0.66 & 0.61 \\
\hline
\end{tabular}

$M E$, metabolisable energy; $V_{A}$, vitamin $A ; V_{D 3}$, vitamin $D_{3} ; V_{E}$, vitamin $E ; V_{K}$, vitamin $K$ $\mathrm{V}_{\mathrm{B} 12}$, vitamin $\mathrm{B}_{12}$.

* Supplied per kg of diet: from 1 to $21 \mathrm{~d}, \mathrm{Fe} 80 \mathrm{mg}, \mathrm{Cu} 7 \mathrm{mg}, \mathrm{Zn} 85 \mathrm{mg}, \mathrm{Mn} 60 \mathrm{mg}$, iodine $0.35 \mathrm{mg}$, Se $0.23 \mathrm{mg}, V_{A} 1.65 \mathrm{mg}, V_{D 3} 0.18 \mathrm{mg}, V_{E} 20 \mathrm{mg}, V_{k} 0.50 \mathrm{mg}, V_{B 12}$ $10 \mathrm{mg}$, thiamin $3.8 \mathrm{mg}$, riboflavin $4.0 \mathrm{mg}$, niacin $25 \mathrm{mg}$, pantothenic acid $10 \mathrm{mg}$, pyridoxine $3.5 \mathrm{mg}$, biotin $0.15 \mathrm{mg}$, folic acid $0.55 \mathrm{mg}$ and choline $1.0 \mathrm{~g}$; from 22 to $42 \mathrm{~d}$, Fe $80 \mathrm{mg}$, Cu $7 \mathrm{mg}, \mathrm{Zn} 60 \mathrm{mg}, \mathrm{Mn} 60 \mathrm{mg}$, iodine $0.35 \mathrm{mg}$, Se $0.15 \mathrm{mg}$, $V_{A} 1.05 \mathrm{mg}, V_{D 3} 0.12 \mathrm{mg}, V_{E} 10 \mathrm{mg}, V_{k} 0.50 \mathrm{mg}, V_{B 12} 10 \mathrm{mg}$, thiamin $2.4 \mathrm{mg}$, riboflavin $4.0 \mathrm{mg}$, niacin $17 \mathrm{mg}$, pantothenic acid $10 \mathrm{mg}$, pyridoxine $3.5 \mathrm{mg}$, biotin $0.15 \mathrm{mg}$, folic acid $0.55 \mathrm{mg}$ and choline $0.75 \mathrm{~g}$; from 43 to $63 \mathrm{~d}, \mathrm{Fe} 80 \mathrm{mg}, \mathrm{Cu} 7 \mathrm{mg}, \mathrm{Zn} 60 \mathrm{mg}$, Mn $60 \mathrm{mg}$, iodine $0.35 \mathrm{mg}$, Se $0.15 \mathrm{mg}, V_{A} 0.525 \mathrm{mg}, V_{D 3} 0.06 \mathrm{mg}, V_{E} 10 \mathrm{mg}$, $\mathrm{V}_{\mathrm{k}} 0.50 \mathrm{mg}, \mathrm{V}_{\mathrm{B} 12} 10 \mathrm{mg}$, thiamin $2.1 \mathrm{mg}$, riboflavin $3.0 \mathrm{mg}$, niacin $15 \mathrm{mg}$, pantothenic acid $10 \mathrm{mg}$, pyridoxine $3.5 \mathrm{mg}$, biotin $0.15 \mathrm{mg}$, folic acid $0.5 \mathrm{mg}$ and choline $0.50 \mathrm{~g}$. $\dagger$ The ME was calculated from data provided by Feed Database in China.

\section{Sample collection}

At $63 \mathrm{~d}$ of age, birds were deprived of feed overnight. Two male birds with similar body weights were chosen randomly from each pen. Birds were weighed, and blood samples were collected from the wing vein in a heparinised tube; serum was obtained after centrifugation ( $3000 \boldsymbol{g}$ for $10 \mathrm{~min}$ ), and the prepared serum was stored at $-80^{\circ} \mathrm{C}$ to be used for anti-oxidative capacity tests, analysis of biochemistry parameters and ELISA. After blood collection, the birds were electrically stunned, exsanguinated and dissected by a trained team to collect tissue samples. The $0.5-\mathrm{cm}$ upper-jejunum wall was fixed in $2.5 \%$ glutaraldehyde $(\mathrm{pH} 7.4$ ) and $4 \%$ paraformaldehyde, respectively, and the mucosa of other jejunum segments and the middle segments of the duodenum were gently scraped. Then, the upper part of the caecum was tied with a string and snap frozen in $\mathrm{N}_{2}$. Moreover, the caecum contents were gently scraped with a blade and stored at $-80^{\circ} \mathrm{C}$ until analysis.

One gram of duodenum and jejunal mucosa samples was homogenised with $9 \mathrm{ml}$ of $0.9 \%$ sterile normal saline on ice and centrifuged at $3500 \boldsymbol{g}$ for $15 \mathrm{~min}$ at $4^{\circ} \mathrm{C}$, respectively. The total protein concentration of the tissue supernatant was measured using a bicinchoninic acid (BCA) protein assay kit strictly according to the manufacturer's protocols (Pierce). The prepared tissue supernatant was stored at $-80^{\circ} \mathrm{C}$ and used in the anti-oxidative capacity test and ELISA.

\section{DNA extraction and 165 ribosomal RNA amplification sequencing}

Total DNA was extracted and purified from approximately $200 \mathrm{mg}$ of individual caecum contents using the QIAamp DNA Stool Mini kit (QIAGEN) according to the manufacturer's instructions. Sequencing was performed at Novogene Bioinformatics Technology Co. Ltd. DNA was amplified using the 515f/806r primer set (515f: 5'-GTG CCA GCM GCC GCG GTA A-3', 806r: 5'-XXX GGA CTA CHV GGG TWT CTA AT-3'). PCR was carried out in $30 \mu \mathrm{l}$ reactions with $15 \mu \mathrm{l}$ of Phusion ${ }^{\circledR}$ High-Fidelity PCR Master Mix (New England Biolabs), $0 \cdot 2 \mu \mathrm{m}$ of forward and reverse primers and approximately $10 \mathrm{ng}$ of template DNA. Thermal cycling consisted of initial denaturation at $98^{\circ} \mathrm{C}$ for $1 \mathrm{~min}$, followed by thirty cycles of denaturation at $98^{\circ} \mathrm{C}$ for $10 \mathrm{~s}$, annealing at $50^{\circ} \mathrm{C}$ for $30 \mathrm{~s}$ and elongation at $72^{\circ} \mathrm{C}$ for $30 \mathrm{~s}$, with a final extension at $72^{\circ} \mathrm{C}$ for $5 \mathrm{~min}$. PCR products were purified using the QIAquick Gel Extraction Kit (QIAGEN). Sequencing libraries were generated using the NEB Next ${ }^{\circledR}$ Ultra $^{\mathrm{TM}}$ DNA Library Prep Kit for Illumina (NEB) following the manufacturer's recommendations, and index codes were added. The library quality was assessed on the Qubit@ 2.0 Fluorometer (Thermo Scientific) and Agilent Bioanalyzer 2100 system. Finally, the library was sequenced on an Illumina HiSeq platform and 250-bp paired-end reads were generated.

\section{Jejunum morphology}

Jejunum samples were embedded in paraffin wax after dehydration and were sectioned at $5 \mu \mathrm{m}$ on a rotary microtome. The sections were further stained with haematoxylin and eosin for morphological analysis, and digital images were obtained under a light microscope (Olympus) ${ }^{(35)}$. Transmission electron microscopy of the colonic tissue was conducted according to a previous study ${ }^{(18)}$.

\section{Detection of goblet cells}

The morphology and distribution of goblet cells in the jejunum epithelium were observed by light microscopy after the sections were stained with periodic acid-Schiff's reaction according to the previous procedures ${ }^{(36)}$. Moditec camera software was applied to take pictures. Five to ten complete intestine villi were selected from each tissue slice, and the number of goblet cells per 100 intestinal epithelial cells was counted.

\section{Terminal deoxynucleotidyl transferase-mediated deoxyuridine triphosphate-biotin nick end labelling assay}

The extent of apoptosis in the jejunum tissue was estimated using the triphosphate-biotin nick end labelling method according to a previous study ${ }^{(37)}$. Briefly, sections were deparaffinised in xylene and hydrated in a graded alcohol series. Endogenous peroxidase was blocked with $2 \% \mathrm{H}_{2} \mathrm{O}_{2}$ in PBS. Terminal deoxynucleotidyl transferase enzyme and digoxigeninlabelled deoxyuridine triphosphate were applied to the sections for $1 \mathrm{~h}$ at $37^{\circ} \mathrm{C}$. Sections were washed in wash buffer and treated with peroxidase-conjugated anti-digoxigenin antibody for $1 \mathrm{~h}$ at room temperature. Treatment with HistoMark Black chromogen solution was performed according to the manufacturer's 
instructions. Sections were stained lightly in haematoxylin and eosin, dehydrated in an alcohol series, cleared in xylene and mounted in Permount.

\section{Relative protein expression by Western blot}

The protein expression of mucin 2 (MUC-2) and tight junction proteins, including claudin-1, in the jejunum tissue was determined by Western blotting. Total protein extraction was performed using Tissue Protein Extraction Reagent (Thermo Pierce, 78510), and protein quantification was then performed using the BCA Quantitation Kit. After SDS-PAGE and membrane transfer, Tris-buffered saline (containing $5 \%$ non-fat dry milk or bovine serum albumin) (Beyotime Biotechnology) was added to the membrane for blocking at room temperature for $1 \mathrm{~h}$. The antibody (1:100) (Beyotime Biotechnology) was then added and incubated overnight at $4{ }^{\circ} \mathrm{C}$, followed by washing the membrane. Secondary antibody (goat anti-Mouse $\operatorname{IgG}(\mathrm{H}+\mathrm{L})$ ) (Beyotime Biotechnology) was added and incubated at room temperature for $1 \mathrm{~h}$ and then washed. SuperSignal ${ }^{\circledR}$ West Dura Extended Duration Substrate was used for Western blot detection. The optical densities of the bands were analysed using Image $\mathrm{J}$ software. $\beta$-Actin was used as an internal control and was found to exhibit no differences between groups. The relative abundance of each target protein was expressed as the ratio of target protein: $\beta$-actin.

\section{Determination of serum and jejunum mucosal biochemistry parameters}

Activities of lipase, trypsin and amylase in the duodenum mucosa were measured using colorimetric methods with a spectrophotometer (Biomate 5; Thermo Electron Corporation). The assays were conducted using assay kits according to the manufacturer's instructions (Nanjing Jiancheng Bioengineering Institute). Individual serum samples were analysed for albumin (no. A028-1), globulin (no. H106), total protein (no. A045-2), uric acid (no. C012) and lysozyme (no. A050-1) using a kit package (Nanjing Jiancheng Bioengineering Institute). Absorbance was measured with an Infinite M200 Pro NanoQuant (Tecan).

\section{Anti-oxidative capacity measurements}

The activities of catalase (no. A007-1), superoxide dismutase (SOD, no. A001-1) and glutathione peroxidase (GSH-Px, no. A005), the levels of total antioxidant capacity (T-AOC, no. A015-1) and malondialdehyde (no. A003-1) in serum and the jejunal mucosa were determined according to the manufacturer's instructions (Jiancheng Bioengineering Institute).

\section{ELISA}

The contents of secretory IL- 6 , TNF- $\alpha$, IL- $1 \beta$, IL-10, IgA and IgG in serum were determined colorimetrically using ELISA kits (Nanjing Jiancheng Institute of Bioengineering). IL-6, TNF- $\alpha$, IL-1 $\beta$, IL-10, secretory IgA (sIgA), endotoxin (ET) and D-lactic acid in the jejunum mucosal supernatant were also determined colorimetrically using ELISA kits (Nanjing Jiancheng Institute of Bioengineering) according to the manufacturer's instructions. Briefly, serum and jejunum mucosal supernatant samples were pipetted into wells coated with antibodies specific for IL-6, TNF- $\alpha$, IL-1 $\beta$, IL-10, IgA, ET, D-lactic acid, IgG and sIgA. After incubation, biotinylated monoclonal secondary antibiotics were added, followed by streptavidin peroxidase. After incubation and rinsing, the bound cytokines were visualised by developing the peroxidase reaction through the addition of $\mathrm{H}_{2} \mathrm{O}_{2}$, and the absorbance of each well was determined with a SpectraMax $5^{(38)}$.

\section{Immunofluorescence}

The distribution of the tight junction zonula occludens protein 1 and occludin in the jejunum tissue was observed by immunofluorescence. In brief, $5-\mu \mathrm{m}$ tissue sections were incubated overnight at $4^{\circ} \mathrm{C}$ with rabbit anti-zonula occludens protein 1 antibody (Servicebio, GB11195) and rabbit anti- $\beta$-occludin antibody (Servicebio, GB11149). The sections were then incubated with Cyanine 3-conjugated goat anti-rabbit IgG $(\mathrm{H}+\mathrm{L})$ secondary antibody (Servicebio, GB21303). Finally, sections were stained with 4',6-diamidino-2-phenylindole solution (Servicebio, G1012) for $10 \mathrm{~min}$ at room temperature in dark conditions, and the images were obtained using a Nikon Eclipse TI-SR fluorescence microscope together with a Nikon DS-U3 imaging system ${ }^{(39)}$.

\section{Statistical analysis}

Raw reads were filtered using Cutadapt software (version 1.9.1), and the sequence database was built using the Ion Plus Fragment Library Kit, 48 rxns (Thermo Fisher Scientific). All clean reads were clustered into operational taxonomic units of $97 \%$, and representative sequences were annotated using an remote display protocol classifier (version 2.2). The top ten relative abundance values for all sample species at the phylum and genus levels were analysed using Mothur software. Subsequently, a ternary plot (R software, version 2.15.3) was used to analyse dominant microorganisms at the species level. Non-metric multi-dimensional scaling was used to assess the clustering of colonic microbial samples. $\alpha$ - and $\beta$-diversities were analysed based on the normalised data output and assessed using the Wilcoxon test. The UniFrac approach was used to estimate pairwise distances between samples and to establish $\beta$-diversity, which was visualised by the principal component analysis and clustering analysis. In addition, based on the taxonomic files obtained from Quantitative Insights In Microbial Ecology (QIIME) analysis, phylogenetic investigation of communities by reconstruction of unobserved states was performed online (http://huttenhower.sph.harvard.edu/galaxy/). The aforementioned process was similar to our previously reported process $^{(40)}$.

All data were analysed using one-way ANOVA followed by Tukey's multiple comparison using SPSS 23.0 software (SPSS Inc.). Data presented are shown as mean values and standard deviations, and values were considered significant at $P<0.05$. Graphs were generated using GraphPad Prism 5.0 software.

\section{Results}

\section{Growth performance of broilers}

The effects of supplemental Ba, Enz or ER on the growth performance of Chinese yellow-feathered broilers are presented in 
Table 2. Effects of Bacillus subtilis DSM 29784, enzyme alone or in combination on the growth performance of broilers

\begin{tabular}{|c|c|c|c|c|c|c|c|}
\hline Items & $A$ & $\mathrm{~B}$ & $\mathrm{C}$ & $\mathrm{D}$ & $E$ & SEM & $P$ \\
\hline \multicolumn{8}{|c|}{ Starter phase (days 1-21) } \\
\hline$A D G(g / d)$ & $19 \cdot 08$ & $19 \cdot 35$ & $18 \cdot 37$ & $18 \cdot 78$ & $18 \cdot 35$ & 0.451 & 0.142 \\
\hline$F: G(g / g)$ & 1.62 & 1.61 & 1.61 & 1.60 & 1.59 & 0.027 & 0.776 \\
\hline Mortality (\%) & $1 \cdot 25$ & 0.42 & 0.83 & 0.83 & 0.42 & 0.007 & 0.736 \\
\hline \multicolumn{8}{|c|}{ Grower phase (days 22-42) } \\
\hline ADG $(g / d)$ & $35 \cdot 25$ & 37.06 & 35.91 & $36 \cdot 16$ & $35 \cdot 30$ & 1.509 & 0.750 \\
\hline ADFI (g/d) & $90 \cdot 67$ & 88.51 & $86 \cdot 21$ & $86 \cdot 28$ & $85 \cdot 45$ & 3.002 & 0.415 \\
\hline$F: G(g / g)$ & $2 \cdot 57^{a}$ & $2 \cdot 39^{b}$ & $2 \cdot 40^{\mathrm{b}}$ & $2 \cdot 39^{b}$ & $2 \cdot 42^{\mathrm{b}}$ & 0.059 & 0.023 \\
\hline Mortality (\%) & 3.38 & 2.51 & 2.52 & 1.68 & 2.51 & 0.009 & 0.430 \\
\hline \multicolumn{8}{|c|}{ Finisher phase (days 42-63) } \\
\hline ADG $(g / d)$ & $47 \cdot 49$ & $46 \cdot 84$ & 45.93 & $45 \cdot 61$ & 43.04 & $2 \cdot 249$ & 0.358 \\
\hline ADFI $(g / d)$ & $140 \cdot 27^{a}$ & $130 \cdot 84^{a, b}$ & $128 \cdot 95^{\mathrm{a}, \mathrm{b}}$ & $128 \cdot 32^{a, b}$ & $119 \cdot 99^{b}$ & $6 \cdot 203$ & 0.052 \\
\hline$F: G(g / g)$ & 2.95 & $2 \cdot 80$ & 2.82 & 2.81 & 2.82 & 0.140 & 0.812 \\
\hline Mortality (\%) & $4 \cdot 38^{a}$ & $1 \cdot 71^{\mathrm{b}}$ & $1.74^{\mathrm{b}}$ & $1 \cdot 28^{b}$ & $0.84^{b}$ & 0.011 & 0.026 \\
\hline \multicolumn{8}{|c|}{ Whole phase (days 1-63) } \\
\hline $\operatorname{ADFI}(g / d)$ & $86 \cdot 48^{a}$ & $83 \cdot 07^{a, b}$ & $81 \cdot 00^{\mathrm{a}, \mathrm{b}}$ & $80 \cdot 88^{a, b}$ & $77 \cdot 66^{b}$ & $2 \cdot 824$ & 0.058 \\
\hline$F: G(g / g)$ & $2.55^{\mathrm{a}}$ & $2.42^{\mathrm{b}}$ & $2 \cdot 43^{\mathrm{b}}$ & $2.41^{\mathrm{b}}$ & $2 \cdot 41^{b}$ & 0.132 & 0.054 \\
\hline Mortality (\%) & $8 \cdot 75^{\mathrm{a}}$ & $4.58^{b}$ & $5 \cdot 00^{b}$ & $3.75^{\mathrm{b}}$ & $3 \cdot 75^{b}$ & 0.015 & 0.015 \\
\hline
\end{tabular}

ADG, average daily gain; ADFI, average daily feed intake; F:G, feed:gain ratio; A, control group; B, Bacillus subtilis DSM 29784 group; C, enzyme (6225 U/g xylanase and 3200 U/g $\beta$-glucanases) group; D, Bacillus subtilis DSM 29784 and enzyme group; E, enramycin group.

a,b Mean values within the same row with unlike superscript letters were significantly different $(P<0.05)$

* Each value represents the mean of six replicates $(n 6) . A D G=$ (last average weight - initial average weight)/feeding days; ADFI = total consumption/(total live chicken weight + total dead chicken weight - total initial weight); $A D F I=A D G \times A D F I$.

Table 2. During the starter phase from 1 to $21 \mathrm{~d}$, these parameters, including average daily gain, ADFI, F:G and mortality, were not different among the five groups. In the grower phase (days 22-42), all four treatments significantly decreased the F:G $(P<0.05)$ compared with that in the control group, similar to that with ER. During the final phase from 43 to $63 \mathrm{~d}$, all four treatments significantly reduced mortality compared with that in the control group, and ER treatment significantly decreased the ADFI. Moreover, considering the entire growth period, the F:G and mortality of broilers subjected to the four treatments (Ba, Enz, Ba + Enz or ER) were significantly decreased when compared with those of the control group. These results indicated that supplementation with Ba, Enz and ER improved the growth performance of broilers.

\section{Immune system and intestinal barrier function}

Digital images and statistical analysis of haematoxylin and eosin-stained sections indicated that the intestinal structure of animals of all treatment groups presented with normal intestinal morphology and a significantly increased villus height:crypt depth ratio compared with that in the control group. Furthermore, all treatment groups showed increased heights and quantity of microvilli, as well as the distribution of epithelial cell junctions in the jejunum (Fig. 1(a) and (b)). Moreover, digital images and statistical analysis of periodic acid-Schiff-stained sections showed that $\mathrm{Ba}$ and $\mathrm{BE}$, similar to that with $\mathrm{ER}$, increased the numbers of goblet cells (Fig. 1(c) and (d)). The nuclei of triphosphate-biotin nick end labelling-positive cells were stained brown. Triphosphate-biotin nick end labellingpositive cells were mainly distributed in the apical region of villi (Fig. 1(e)). Compared with that in control broilers, the number of triphosphate-biotin nick end labelling-positive cells in the other four treatment groups showed no significant changes (Fig. 1(f)). To further investigate the effect of $\mathrm{Ba}$, Enz or ER on the intestinal physical barrier function, the relative protein expression of MUC-2 and the tight junction protein-related protein claudin-1 were examined. Enz and BE significantly increased MUC-2 and claudin-1 expression in the jejunal mucosa compared with that in the control or ER group $(P<0.01)$, whereas feed supplemented with Ba did not induce any change in MUC-2 expression and reduced claudin-1 expression compared with that in the control group (Fig. 2(a) and (b)). To confirm the impact of Ba, Enz or ER on the expression of tight junction and adherence junction proteins, we further performed immunofluorescence analysis and the resulting images demonstrated a similar result to epithelial cell protein junction expression in the jejunal mucosa (Fig. 2(c)).

\section{Biochemical indices in the duodenum and serum}

Compared with that in the control group, BE significantly increased lipase activity in the duodenum among the five treatments (Fig. 3(a); $P<0.05$ ), whereas no differences were observed in the activities of trypsin and amylase. The serum ET levels in both the Ba and BE groups were markedly decreased by 18.92 and $10 \cdot 14 \%$, respectively. However, no significant changes were observed in the contents of uric acid and D-lactic acid in the serum of broilers among the five treatment groups (Fig. 3(b))

\section{Antioxidant-related parameters in serum and jejunum mucosa}

Antioxidant parameters in the jejunum are shown in Fig. 4(a). Ba significantly increased SOD activity $(P<0 \cdot 05)$. Further, the GSH-Px activity in both the $\mathrm{Ba}$ and $\mathrm{BE}$ groups was higher 
(a)



(b)

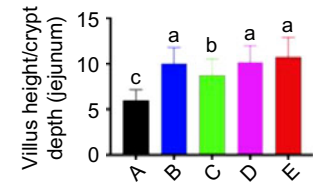

(d)
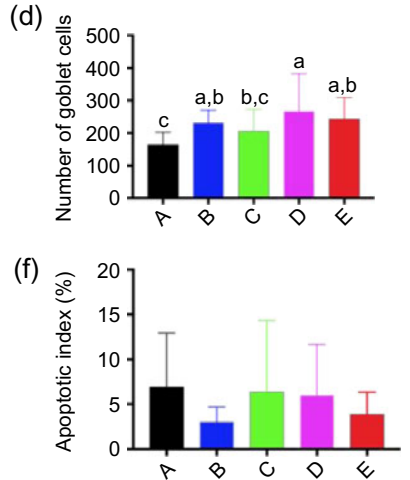

Fig. 1. (a) Representative haematoxylin and eosin (H\&E)-stained images (top, scale bars $=80 \mu \mathrm{m}$ ) and transmission electron microscopy images (bottom, scale bars $=1 \mu \mathrm{m}$; red arrows indicate epithelial cell junctions) of cross-sections of the bird's jejunum. (b) Statistical analysis of the histological parameter 'villus height:crypt depth ratio' in the jejunum. (c) Representative images of periodic acid-Schiff's (PAS) reaction-stained jejunum sections in broilers (400x). (d) Number of PAS-stained goblet cells. (e) Representative images of cross-sections of the broilers jejunum stained for triphosphate-biotin nick end labeling (TUNEL) (200x). (f) Quantification of

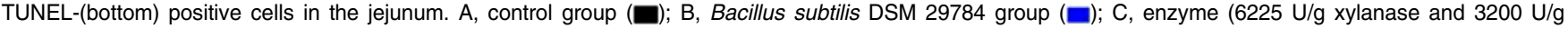

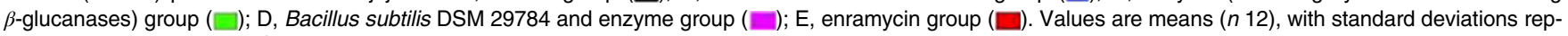
resented by vertical bars. ${ }^{\mathrm{a}, \mathrm{b}, \mathrm{c}}$ Mean values with unlike letters between different groups were significantly different $(P<0.05)$.

(a)

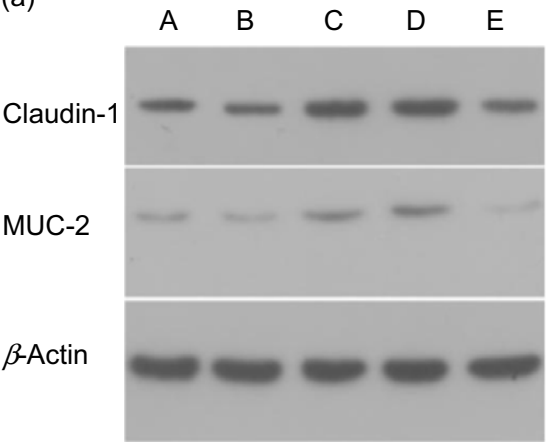

(c)

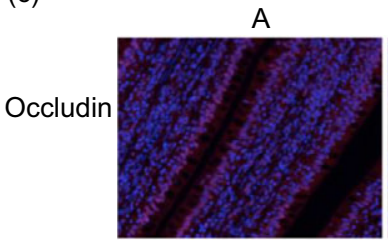

$\mathrm{ZO}-1$

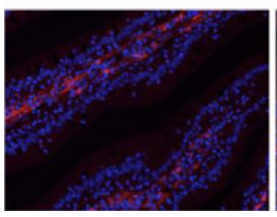

B


(b)

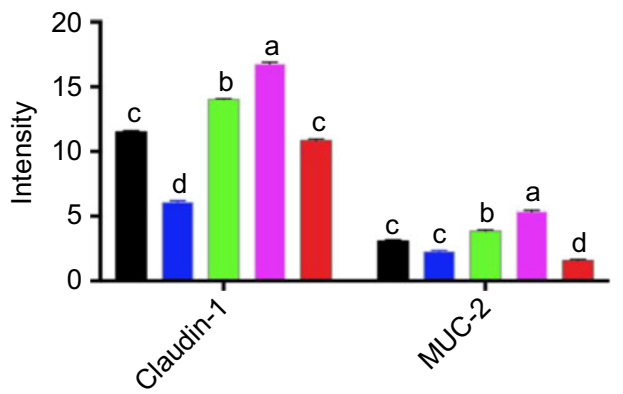

C
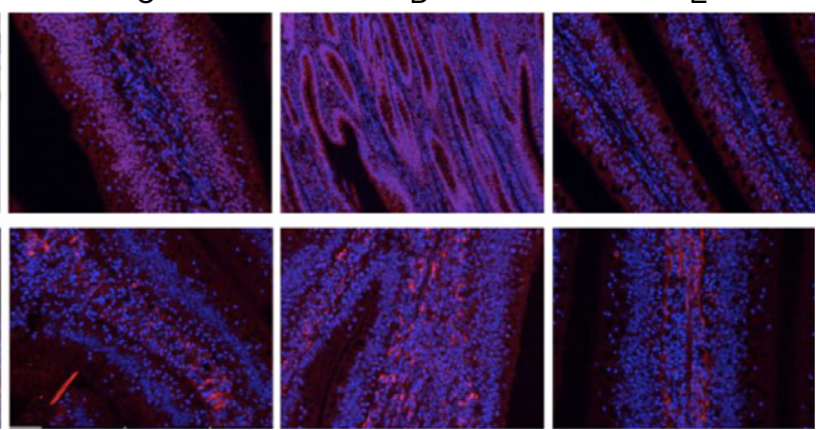
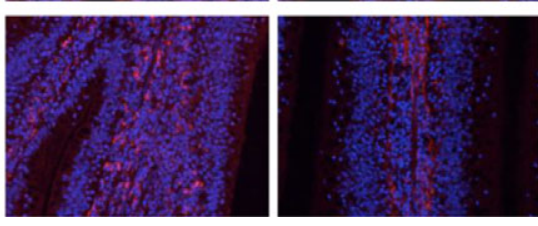

Fig. 2. (a) Expression of mucin 2 (MUC-2) and claudin-1 in jejunum tissue was determined by Western blot. (b) Relative changes in the density of MUC-2 and claudin-1 were analysed. Data are presented as relative MUC-2 and claudin-1 band intensity normalised to $\beta$-actin band intensity. Values are means ( $n 12)$, with standard deviations represented by vertical bars. (c) The expression of occludin and zonula occludens protein 1 (ZO-1) was measured using immune staining. $4^{\prime}, 6$-Diamidino-2-phenylindole was used for staining nucleus. A, control group ( $\square$ ); B, Bacillus subtilis DSM 29784 group ( $\square$ ); C, enzyme (6225 U/g xylanase and 3200 U/g $\beta$-glucanases) group

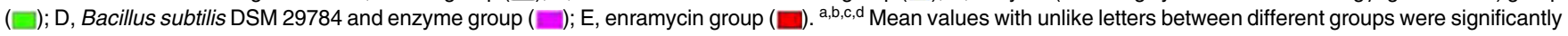
different $(P<0.05)$. 
(a)

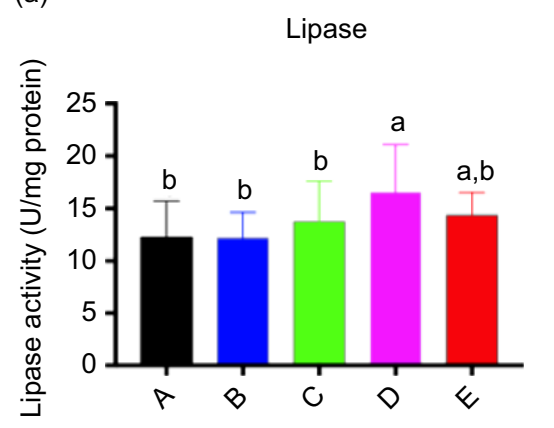

(b)

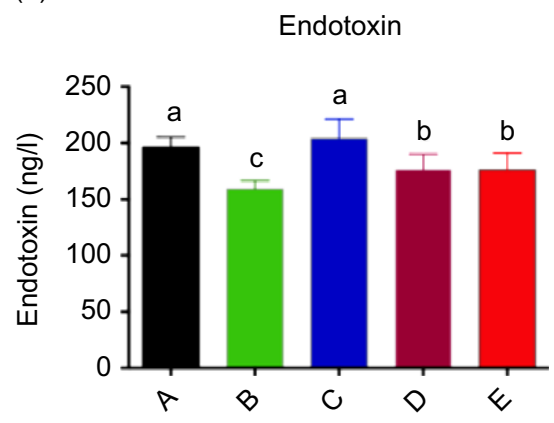

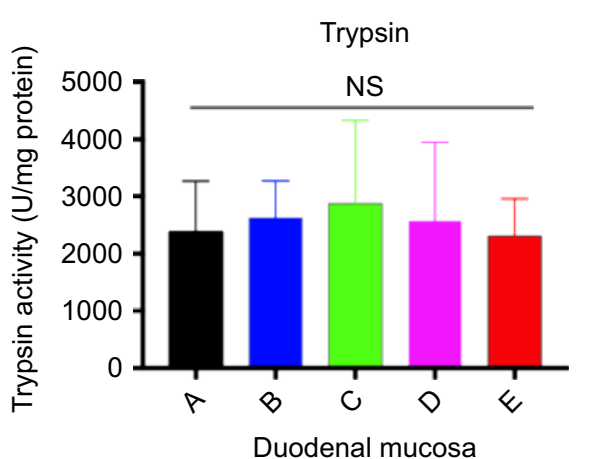


Fig. 3. Duodenal mucosa (a) and serum (b) biochemistry parameters of broilers chickens supplemented with Bacillus subtilis DSM29784, enzyme alone or in combi-

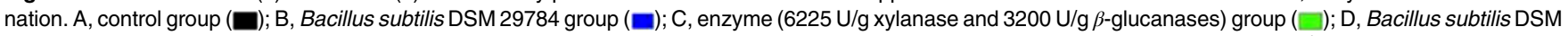
29784 and enzyme group $(\square)$; E, enramycin group $(\square)$. Values are means ( $n$ 12), with standard deviations represented by vertical bars. ${ }^{\text {a,b,c }}$ Mean values with unlike letters between different groups were significantly different $(P<0.05)$.

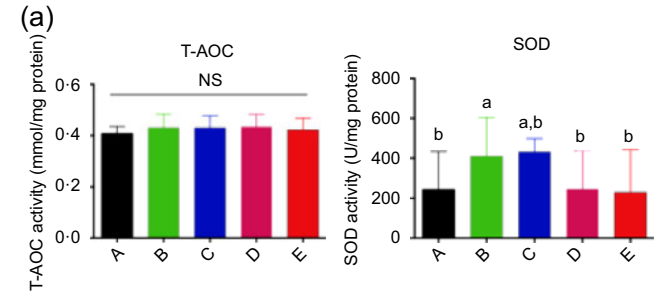

(b)
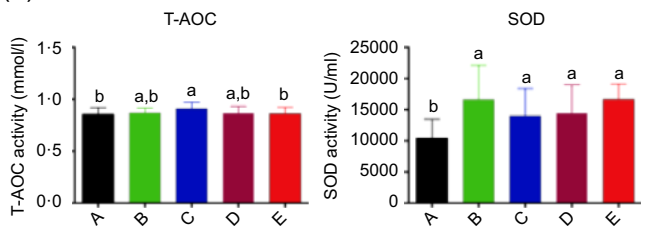

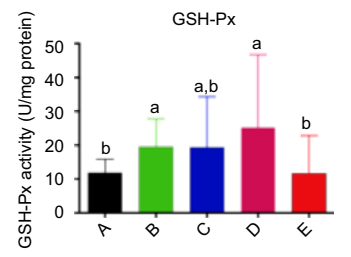

Jejunal mucosa
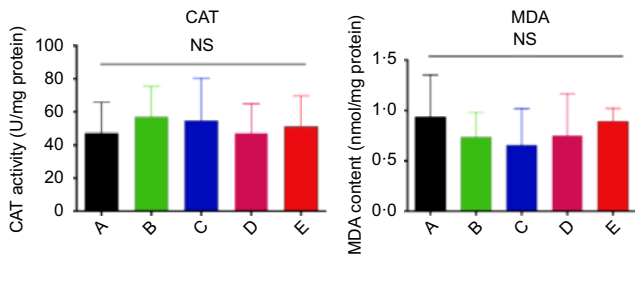

CAT
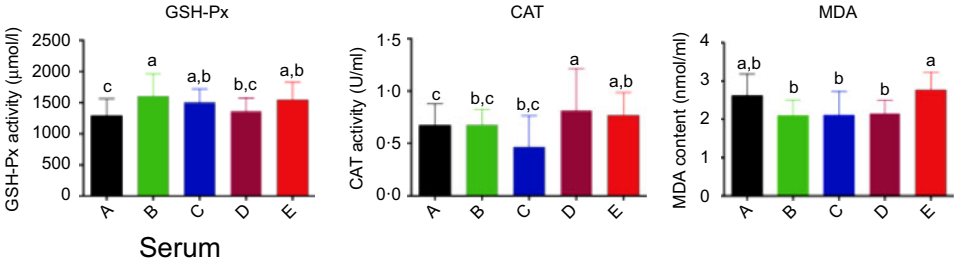

Fig. 4. Effects of Bacillus subtilis DSM29784, enzyme alone or in combination on anti-oxidative capacity of broilers. The activities of anti-oxidative enzymes and levels of total antioxidant capacity (T-AOC) and malondialdehyde (MDA) were determined in jejunal mucosa (a) and serum (b), respectively. SOD, superoxide dismu-

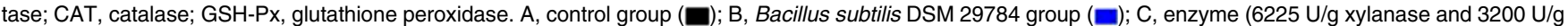

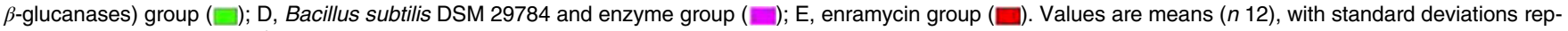
resented by vertical bars. ${ }^{a, b, c}$ Mean values with unlike letters between different groups were significantly different $(P<0.05)$.

than that in the control or ER group $(P<0 \cdot 05)$. However, no significant difference was found among the Ba, Enz, BE and ER groups in other antioxidant parameters including T-AOC, catalase and MAD (Fig. 4(a)).
Fig. 4(b) represents the anti-oxidative parameters of serum. Compared with that in the control group, Enz significantly increased serum T-AOC $(P<0.05)$, and $\mathrm{BE}$ increased catalase activity $(P<0.05)$, whereas the GSH-Px activity in 
(a)
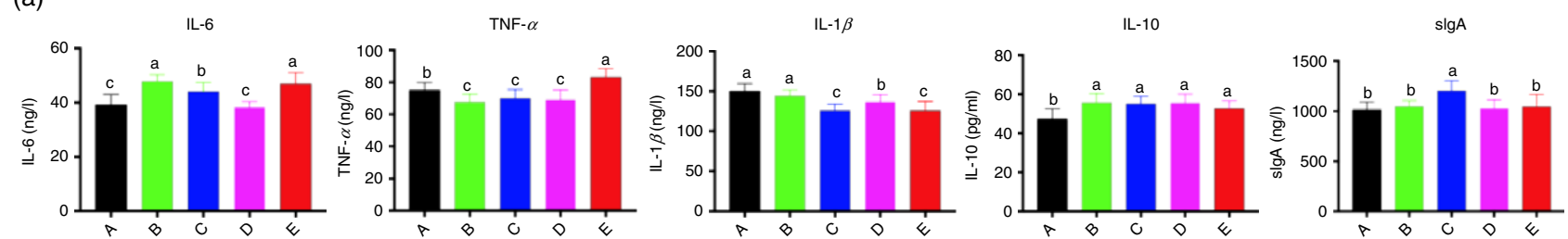

(b)
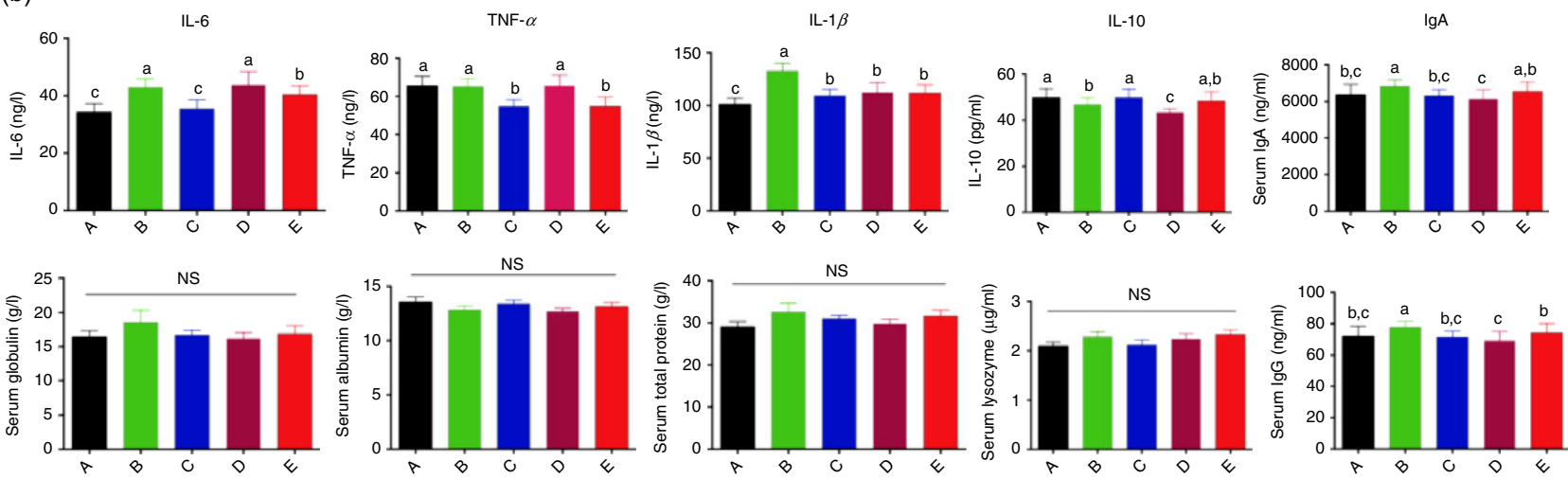

Fig. 5. Effects of Bacillus subtilis DSM29784, enzyme alone or in combination on immune response of broilers in jejunal mucosa (a) and serum (b), respectively. A,

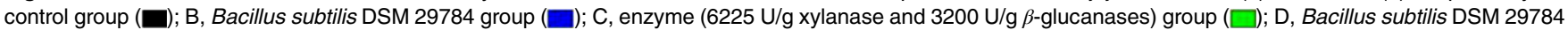
and enzyme group $(\square)$; E, enramycin group; slgA, secretory IgA. Values are means ( $n 12)$, with standard deviations represented by vertical bars. ${ }^{\text {a,b,c }}$ Mean values with unlike letters between different groups were significantly different $(P<0.05)$.

the Ba and Enz groups was significantly increased $(P<0 \cdot 05)$. In addition, the serum SOD activity was significantly increased, whereas the malondialdehyde level was significantly decreased in the $\mathrm{Ba}$, Enz and $\mathrm{BE}$ treatment groups $(P<0 \cdot 05$; Fig. 4(b)).

\section{Immune response in serum and jejunum mucosa}

Cytokine secretion in the jejunum mucosa is shown in Fig. 5(a). Compared with that in the control or ER group, the IL-6 level in both the $\mathrm{Ba}$ and Enz groups was markedly increased by 22.22 and $12.50 \%$, respectively, whereas IL- $1 \beta$ was decreased in the Enz and BE groups by 16.07 and $8.62 \%$, respectively. TNF- $\alpha$ was significantly decreased $(P<0.05)$, whereas IL-10 was increased $(P<0.05)$ in the $\mathrm{Ba}$, Enz and $\mathrm{BE}$ treatment groups (Fig. 5(a)). sIgA in the Ba group was higher than that in the other four groups $(P<0.05$; Fig. 5(a)).

The immune parameters of serum are presented in Fig. 5(b). Compared with that in the control group, the serum IL-6 level in both the $\mathrm{Ba}$ and $\mathrm{BE}$ groups was significantly increased by $25 \cdot 18$ and $23.92 \%$, respectively, and IL-10 was decreased by 5.90 and $13.01 \%$, respectively. Serum IL- $1 \beta$ in the Ba group was higher than that in the other four groups, whereas TNF- $\alpha$ levels were significantly decreased compared with those in the control group. In addition, IgA and IgM in the Ba group were higher than that in the other four groups. No significant changes were observed in serum globulin, albumin and total protein levels and in the activity of lysozyme among the five treatment groups.

\section{Microbial community structure of the caeca}

The number of operational taxonomic units in the control group was 801 , whereas that in the other four experimental groups was 799, 764, 786 and 794, respectively. Operational taxonomic units in common were 651 and the common ratio was $81.27 \%$, suggesting that there were still a few differences (Fig. 6(a)). Furthermore, we determined the bacterial richness and diversity of the caeca microbiota in broilers among the five treatment groups. The principal dimension (PD) whole tree index was higher in the BE and ER treatment groups than in the control group (Fig. 6(b)). Moreover, BE-treated broilers exhibited a significantly higher $\beta$-diversity parameter based on unweighted UniFrac than the control or Ba treatment groups (Fig. 6(c)). Clustering analysis revealed short UniFrac distances among the Enz, BE and ER treatment groups and long branches separating the samples from the control and those three groups (Fig. 6(d)). However, there was no significant difference between the control and $\mathrm{Ba}$ treatment groups. The dissimilarity in the caeca microbial community was greatest between the control and BE treatment groups, as with ER. Ternary plot analysis indicated that Bacteroides barnesiae, Bacteroides dorei, Bacteroides fragilis and Bacteroides sp. dominated the caecal microbial community of all broilers on day 63. Notably, the antibiotic-treated group was more similar to the Ba or Enz treatment groups than to the control group (Fig. 6(e)).

The dominant phyla in the caeca across five treatment groups were Bacteroidetes, Firmicutes and Proteobacteria, together accounting for more than $90 \%$ of the total sequences (Fig. 6(f)). 
(a)

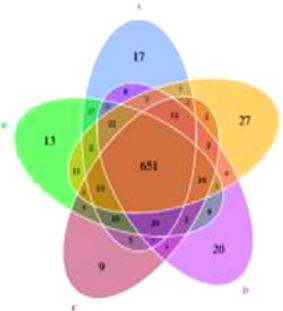

(e)

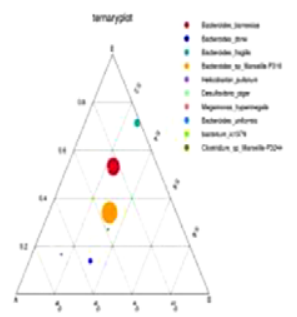

(f)

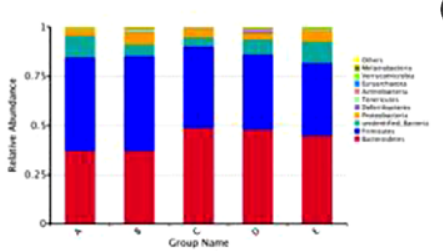

(b)

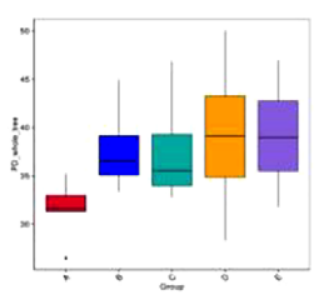

(c)

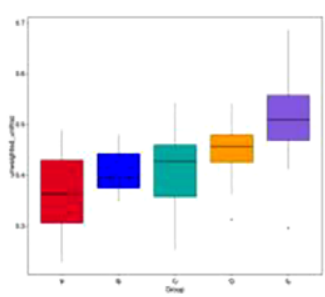

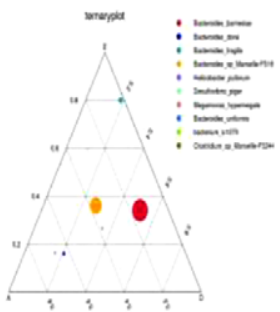

(g)

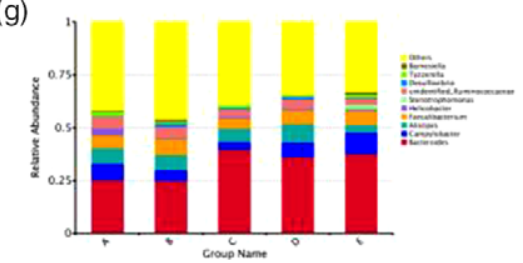

(d)

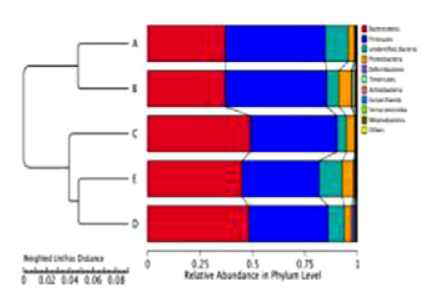

(h)

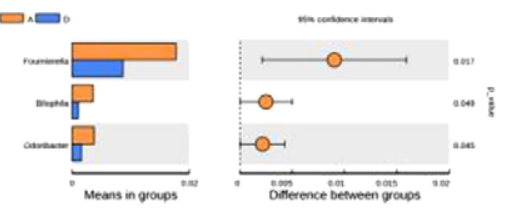

(i)

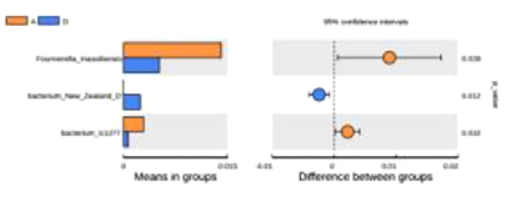

Fig. 6. The caecal bacterial community of broilers fed dietary Bacillus subtilis DSM 29784, multi-enzyme or enramycin supplementation among the five treatments (A, B, $\mathrm{C}, \mathrm{D}$ and $\mathrm{E})$. (a) The Venn diagram presents overlaps among the $\mathrm{A}-\mathrm{E}$ treatments, as well as the unique operational taxonomic units for each group. (b) $\alpha$-Diversity of gut microbial was analysed among A-E treatments by determination of principal dimension (PD) whole tree index. (c) $\beta$-Diversity based on unweighted UniFrac of caecum microbiota among the five groups. (d) Unweighted pair group method with arithmatic mean (UPGMA) clustering tree with weighted UniFrac distances. (e) Ternary plot of A-B-E, A-C-E and A-D-E. Different size of circles corresponds to the abundance of bacteria. The relative abundances of species at the phylum level (f) and genus level (g), respectively. The $t$ test analyses of the abundances between A and D in differential species: (h) genus level and (i) species level. A, control group; B, Bacillus subtilis DSM 29784 group; C, enzyme (6225 U/g xylanase and 3200 U/g $\beta$-glucanases) group; D, Bacillus subtilis DSM 29784 and enzyme group; E, enramycin group.

Compared with those in the control group, birds in the Enz and BE treatment groups at these three levels had higher relative abundances of Bacteroidetes and Proteobacteria and a lower relative abundance of Firmicutes in the caeca microbiota, as with ER. However, the greatest abundance of Proteobacteria was observed in the Ba treatment group, whereas no significant changes were observed between the control and Ba treatment groups in the relative abundance of Bacteroidetes and Firmicutes (Fig. 6(f)). At the genus level, an increase in the abundance of Bacteroides was also detected in the other four treatment groups compared with that in the control group (Fig. $6(\mathrm{~g})$ ). Further analysis revealed that BE treatment resulted in lower abundances of Fournierella, Bilophila, Odoribacter, Fournierella massiliensis, bacterium New Zealand $D$ and bacterium ic1277 in the caecum compared with those in the control group (Fig. 6(h) and (i)).

To further determine the relationships among different microbes in the five treatment groups, we also performed network analysis of gut microbiota by calculating Spearman's correlation coefficients among all genera. Our results revealed a larger proportion of negative correlations in the microbial community and fewer interactions of gut microbiota in the Enz, BE or ER treatment groups as indicated by lower coefficients of network analysis including cluster coefficients network diameter, modularity, clustering coefficient average degree and average path length/mean distance. In contrast, higher coefficients of network analysis were observed in the Ba treatment group based on higher network diameter, modularity, clustering coefficient and average path length (Fig. 7(a)-(f)).

\section{Predicted function of caecal microbiota}

To investigate the differences in microbiota functions among the five groups, we performed a functional analysis of microbes (using phylogenetic investigation of communities by reconstruction of unobserved states). Third-level Kyoto Encyclopedia of Genes and Genomes analysis showed that purine metabolism, homologous recombination, chromosome, energy metabolism, amino acid-related enzymes, ribosome biogenesis, pyrimidine metabolism and DNA replication, repair and recombination proteins were enriched in BE-treated broilers compared with that in the control or ER-treated birds. Meanwhile, amino sugar and nucleotide sugar metabolism, cysteine and methionine metabolism, transcription machinery, starch and sucrose metabolism, peptidases, general function prediction only, fructose and mannose metabolism, and arginine and proline metabolism pathways were enriched in the Enztreated birds compared with those in the control or ER-treated broilers. Moreover, the microbiota of the Ba treatment group displayed a higher abundance of functions involving metabolic 
(a)

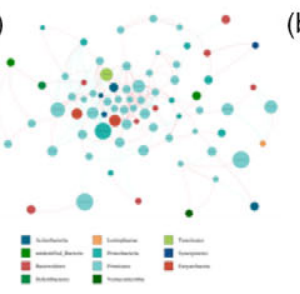

(b) :

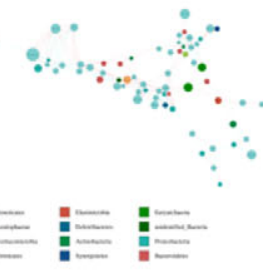

(c)

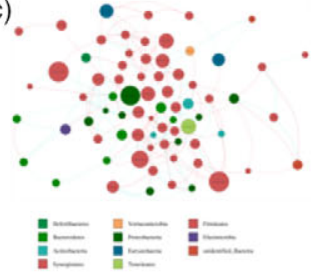

(d) :

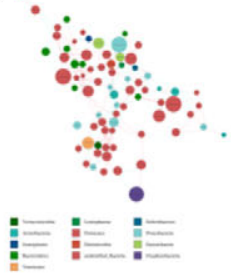

(e)



(f)

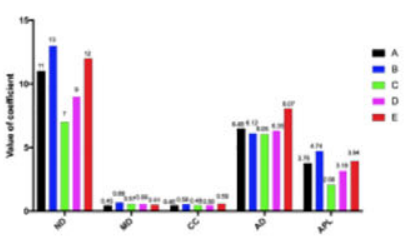

(g)

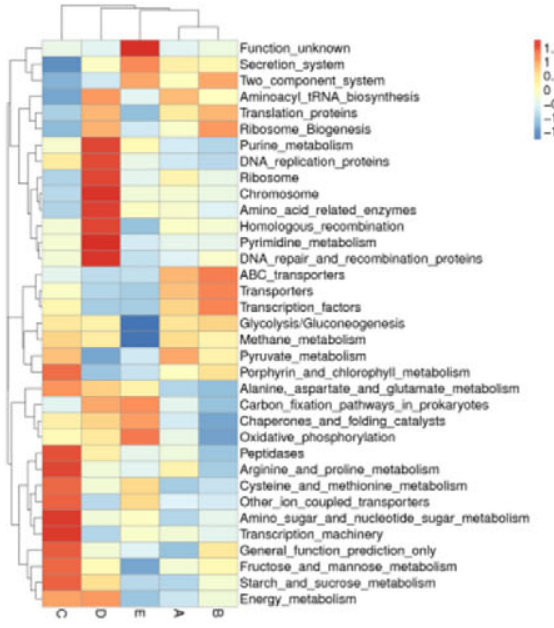

Fig. 7. (a-e) Network analysis of microbial community in A, B, C, D and E groups based on the calculation of Spearman's correlation coefficients. Nodes indicate taxonomic units at the genus level, while red lines indicate positive correlations and blue lines indicate negative correlations. The colour of a node represents the phylum to which it belongs, and the size of a node represents the relative abundance of a genus. The thickness of a line indicates the strength of correlation. (f) Typical coefficients derived from network analysis in the five groups (CC, clustering coefficient, GD, graph density, AD, average degree, APL, average path length). (g) Functional abundance cluster analysis. A, Control group; B, Bacillus subtilis DSM 29784 group; C, enzyme (6225 U/g xylanase and 3200 U/g $\beta$-glucanases) group; D, Bacillus subtilis DSM 29784 and enzyme group; E, enramycin group.

pathways such as transporters, transcription factors and ribosome biogenesis, compared with those in the other four groups (Fig. 7(g)).

\section{Discussion}

As food safety and environmental contamination are receiving increasing attention, antibiotic replacement has become a trend. Probiotics and feed enzymes have been widely used as antibiotic replacements to enhance animal growth and intestinal health ${ }^{(41,42)}$. Çinar et $a l .^{(43)}$ demonstrated significant improvement in the feed conversion ratio when prebiotics and probiotics were supplemented together, suggesting synergism between them. Moreover, a glucose oxidase and Bacillus amyloliquefaciens SCO6 combination had a better anti-apoptotic effect than glucose oxidase alone ${ }^{(18)}$. A combination of the probiotic strains Lactobacillus plantarum KY1032 and Lactobacillus curvatus HY7601 was more effective in inhibiting the gene expression of various fatty acid synthesis enzymes in the liver, concomitant with decreases in fatty acid oxidation-related enzyme activities and their gene expression ${ }^{(44)}$.

During the starter phase from 1 to $21 \mathrm{~d}$, there was no significant effect on average daily gain, ADFI, F:G and mortality due to Ba or Enz treatment. In contrast, the current study showed that all treatments significantly decreased the F:G during the grower phase compared with that in the control group, similar to that with ER. Moreover, considering the whole growth period, the $F: G$ and mortality of broilers in all treatment groups decreased. These results might be due to the fact that Chinese yellow-feathered broilers mature at a moderate pace and grow slowly in the start phase. In addition, barley was used in the diet during the growth and final phases, and the improvement of the growth performance of broilers might be due to the addition of
Ba or Enz. As a green feed additive, B. subtilis has been widely promoted as an alternative to replace in-feed antibiotics due to its abilities to improve livestock production and efficiency ${ }^{(45)}$. In addition, many studies have shown that xylanase and $\beta$-glucanase can stimulate the growth response and feed efficiency of chickens ${ }^{(28)}$, turkeys ${ }^{(30)}$, pigs ${ }^{(46)}$ and fish ${ }^{(25)}$. Our data are in agreement with these findings. However, ER treatment significantly decreased the ADFI compared with that in the control group during the final phase; this might be due to the significantly increased mortality in the control group.

The concept of 'gut health' is complex but is now well recognised as a key driver of animal performance ${ }^{(47)}$. The intestinal barrier comprises four main components, the physical, chemical, immunological and microbiological barriers ${ }^{(48)}$. The health of the gastrointestinal tract affects the digestion, absorption and metabolism of nutrients, disease resistance and immune responses ${ }^{(49,50)}$. A complete small intestinal structure is important for digestive and absorptive functions of the small intestine and is closely related to the morphological changes in small intestinal villus length and crypt depth ${ }^{(51)}$. Moreover, the intestinal epithelium serves as a protective barrier and plays a beneficial role in nutrient absorption; its morphology is also used to assess intestinal development and function ${ }^{(40)}$. Al-Fataftah \& Abdelqader ${ }^{(52)}$ indicated that dietary supplementation with B. subtilis enhances the intestinal barrier function in animal models. In the present study, the intestinal morphology indicated that all treatments had positive effects on the tight junctions or microvillus length, width and density compared with those in the control group. Goblet cells synthesise and secrete lubricant mucus that forms a mucus layer in the small intestine to protect the epithelial cells ${ }^{(53)}$. In the present study, we observed that the number of goblet cells was obviously increased in the jejunum of chickens fed the $\mathrm{Ba}, \mathrm{BE}$ or ER diets when compared with that in chickens fed the control diet (Fig. 1(d)). In addition, tight 
junctions are essential components of intestinal mucosal barriers, providing paracellular permeability ${ }^{(54)}$. The MUC-2 protein is a major component of the intestinal mucus layer, which plays an important role in preventing intestinal damage by bacteria and lubricating the small intestine to maintain mucosal barrier functions ${ }^{(55)}$, whereas a decrease in MUC-2 induces an inflammatory immune response ${ }^{(56)}$. In the present study, our results showed that the relative protein expression of MUC-2 and tight junction protein-related protein claudin- 1 was increased in the Enz and BE groups compared with that in the control or ER group. This finding demonstrated that Enz or BE might enhance the intestinal barrier function.

Endotoxins are also referred to as lipopolysaccharides, which are cell wall components of Gram-negative bacteria. Minor or trace amounts of ET, even at the pico-gram scale, have the potential to elicit an inflammatory response in the host once they enter the interior circulation ${ }^{57,58)}$. However, ET concentrations can become fatal if they reach up to $1 \mathrm{~g}$, especially in the intestines ${ }^{(59)}$. A previous study reported that damage to the intestinal tract epithelium leads to the enormous absorption of ET from the intestinal tract ${ }^{(57)}$. In the present study, reduced serum ET content was found in the Ba, BE and ER groups, which indicated that $\mathrm{Ba}, \mathrm{BE}$ and $\mathrm{ER}$ might improve the integrity of the intestinal tract epithelium.

The intestinal environment plays a critical role in maintaining good health ${ }^{(60)}$. As is known, an increase in lipase activity leads to more effective fat absorption ${ }^{(61)}$. Yango et al. demonstrated that lyophilised photosynthetic bacterial cells at $1 \mathrm{~g} / \mathrm{kg}$ and lyophilised Bacillus sp. at $1 \mathrm{~g} / \mathrm{kg}$ in combination highly increase the amylase and lipase enzyme activities of common Cyprinus carpio ${ }^{(62)}$. However, Ogawa et al. ${ }^{(63)}$ indicated that Lactobacillus gasseri SBT2055 significantly decreases lipase activity to increase the size of fat emulsion droplets and suppress lipid absorption. In the present study, we found that broilers in the BE group had much higher activity of lipase in the contents of the jejunum than broilers fed a control diet, whereas no difference was found with Ba or Enz supplementation alone.

Various stressful conditions enhance the production of free radicals and restrict the growth performance of chickens in the poultry industry ${ }^{(64)}$. The excessive formation of free radicals contributes to a detrimental biological condition, namely oxidative stress, which gives rise to performance losses, meat deterioration, intestinal dysfunction and immunosuppression of broilers ${ }^{(65-67)}$. Antioxidants interact in a complex network to recycle and regenerate one another and protect against oxidative stress-induced intestinal diseases ${ }^{(68)}$. Probiotics are regarded as a natural source that can scavenge excess free radicals, as well as improve the antioxidant capacity of animals ${ }^{(69)}$. The antioxidant system includes both natural and synthetic anti-oxidative enzymes ${ }^{(70)}$. Cellular resistance to oxidative agents is controlled by several key enzymes such as T-AOC, GSH-Px, SOD and catalase $^{(71)}$. In addition, malondialdehyde is associated with lipid peroxidation and avian stress ${ }^{(72)}$. In the present study, Ba administration increased the activities of GSH-Px and SOD in the serum and the jejunum (Fig. 4(a) and (b)), whereas Enz increased the activities of serum T-AOC, SOD and GSH-Px. However, BE did not have a better effect than Ba or Enz alone on antioxidant capacity. These results indicate that Ba and Enz, alone or in combination, enhance the antioxidant capacity of broilers.

Intestinal dysbiosis associated with immunological deregulation, leaky gut, bacterial translocation and systemic inflammation has been associated with autoimmune diseases ${ }^{(73)}$. The innate immune system is composed of a network of cells including neutrophils, natural killer and natural killer $\mathrm{T}$ cells, monocytes/macrophages and dendritic cells that mediate the earliest interactions with pathogens ${ }^{(74)}$. Poultry can generate cytokines inside their bodies, which can influence the immune system. Cytokines are of importance within the innate immune system ${ }^{(75)}$. As shown in Fig. 5, supplementation with Ba or Enz significantly increased the anti-inflammatory cytokine IL-10 in the jejunum and reduced the pro-inflammatory cytokine TNF- $\alpha$, with increased IL-6 content; moreover, Enz decreased IL- $1 \beta$ secretion and resulted in the highest sIgA level among the five groups. In addition, Ba significantly increased serum IgA and IgG contents compared with those in the control or ER group. Inflammatory cytokine production can enhance the immune response to protect against pathogen invasion, whereas an excessive inflammation response leads to tissue damage ${ }^{(76)}$. In addition, SIgA can protect the intestinal tract from dietary and microbial antigens ${ }^{(77)}$. sIgA inhibits the adherence and invasion of potentially harmful antigens into the mucosa and neutralises toxins and virulence factors from microbial pathogens ${ }^{(78)}$. Taken together, probiotics or enzymes might activate the immune response to protect against pathogen invasion and hence maintain intestinal homeostasis by a balance between pro-inflammatory and anti-inflammatory responses.

Gut microbiota might function to prevent pathogens from colonisation of the intestinal tract. The importance of commensal gut microbiota is highly important for the normal functioning of the immune apparatus of the gut ${ }^{(31,79)}$. Various studies have demonstrated that probiotics can positively regulate the composition of intestinal microbiota ${ }^{(12,80)}$. Lei et al $^{(81)}$ demonstrated that B. amyloliquefaciens can dramatically decrease the population of Escherichia coli and increase Lactobacillus populations in the caecum. Dietary supplementation with probiotics increases the Bifidobacterium and Lactobacillus concentrations ${ }^{(82)}$ and increases the activities of caecal microflora ${ }^{(83)}$. The administration of Clostridium butyricum was found to decrease E. coli and Salmonella and Clostridium perfringens counts and increase Lactobacillus and Bifidobacterium counts in the caeca $^{(84)}$. In addition, xylanase and $\beta$-glucanase supplementation influences the microbiota of broiler chicken caeca and might reduce potentially pathogenic Enterobacteriaceae populations ${ }^{(29)}$. Our work demonstrated that supplementation with Ba, ER or BE alters the structure of caecal microflora, with observably distinctive operational taxonomic units appearing and with markedly different community structures based on the principal component analyses. The $\alpha$-diversity according to the PD whole tree and $\beta$-diversity parameter based on unweighted UniFrac were significantly increased in the BE group; moreover, the clustering analysis revealed short UniFrac distances between the BE and ER groups. Kristensen et al. ${ }^{(80)}$ demonstrated that probiotic supplementation significantly modifies the overall structure of the faecal bacterial community in terms of $\beta$-diversity when compared to that with the placebo. 
According to our findings, the $\mathrm{Ba}$ and Enz combination had a better effect on intestinal microbiota richness. The results showed that the relative abundances of Bacteroidetes and Proteobacteria in the caeca of broilers were increased, as with ER, and Bacteroidetes and Firmicutes were the two most abundant phyla of these broiler chickens. This result was similar to that of a previous study indicating that Bacteroidetes and Firmicutes are associated with an absolute advantage in piglet guts ${ }^{(85)}$. Firmicutes can maintain intestinal health by producing SCFA, inhibiting inflammation, providing energy for intestinal epithelial cells and contributing to animal energy metabolism $^{(86,87)}$. However, Proteobacteria are a potential diagnostic signature of dysbiosis and risk of disease, as a sustained increase in the abundance of this phylum often can result in an imbalanced gut microbiota ${ }^{(88)}$. Intestinal microbiota are known to have physiological effects on a host in terms of metabolising dietary nutrients, producing SCFA from indigestible carbohydrates, synthesising amino acids and vitamins and regulating metabolism ${ }^{(87,89)}$. According to our findings, purine metabolism, homologous recombination, chromosome, energy metabolism, amino acid-related enzymes, ribosome biogenesis, pyrimidine metabolism and DNA replication, repair and recombination proteins were enriched in BE-treated broilers.

In summary, dietary treatment with $\mathrm{Ba}$, Enz or BE was found to have beneficial effects on the growth performance of broilers. This enhancement was associated with the positive influence of tract digestibility and anti-oxidative capacity, immune function and intestinal microbiota. In addition, the results suggested that BE exerts a better effect, compared to that with Ba or Enz alone, on the growth performance, digestive enzyme activity and the population of intestinal microbiota. Therefore, according to our research, Ba or Enz could be used as an alternative to antibiotics in broiler chickens.

\section{Acknowledgements}

The financial support provided by National Key R\&D Program of China (project no. 2016YFD0500500, Beijing, China), Zhejiang Province Key R\&D Program of China (project no. 2018C02035, Hangzhou, China) and China Agriculture Research System (project no. CARS-41-G20, Beijing, China) is gratefully acknowledged.

The authors' contributions were as follows: X. Z. and X. Z. designed the experiments. Y. W., C. H., L. J., J. W., K. L. and D. W. performed the animal experiments. Y. W. performed the statistical analysis. Y. W. and G. C. drafted the paper. All authors approved the final manuscript and contributed.

The authors declare that there are no conflicts of interest.

\section{References}

1. Kiarie E, Walsh M \& Nyachoti C (2016) Performance, digestive function, and mucosal responses to selected feed additives for pigs. J Anim Sci 94, 169-180.

2. Dahiya J, Wilkie D, Van Kessel A, et al. (2006) Potential strategies for controlling necrotic enteritis in broiler chickens in post-antibiotic era. Anim Feed Sci Technol 129, 60-88.
3. Miles RD, Butcher GD, Henry PR, et al. (2006) Effect of antibiotic growth promoters on broiler performance, intestinal growth parameters, and quantitative morphology. Poult Sci $\mathbf{8 5}$, 476-485.

4. Asai M, Muroi M, Sugita N, et al. (1968) Enduracidin, a new antibiotic. II. Isolation, characterization. J Antibiot 21, 138-146.

5. Benno Y, Endo K \& Mitsuoka T (1988) Isolation of fecal Clostridium perfringens from broiler chickens and their susceptibility to eight antimicrobial agents for growth promotion. Nibon Juigaku Zasshi 50, 832-834.

6. Songer JG (1996) Clostridial enteric diseases of domestic animals. Clin Microbiol Rev $9,216-234$.

7. Smith DL, Harris AD, Johnson JA, et al. (2002) Animal antibiotic use has an early but important impact on the emergence of antibiotic resistance in human commensal bacteria. Proc Natl Acad Sci U S A 99, 6434-6439.

8. Miller M (2015) The White House forum on antibiotic stewardship impacts labs across the U.S. MLO Med Lab Obs 47, 28.

9. Wierup M (2001) The Swedish experience of the 1986 year ban of antimicrobial growth promoters, with special reference to animal health, disease prevention, productivity, and usage of antimicrobials. Microb Drug Resist 7, 183-190.

10. Dibner J \& Richards J (2005) Antibiotic growth promoters in agriculture: history and mode of action. Poult Sci $\mathbf{8 4}$, 634-643.

11. Khan RU, Naz S, Dhama K, et al. (2016) Direct-fed microbial: beneficial applications, modes of action and prospects as a safe tool for enhancing ruminant production and safeguarding health. Int J Pharmacol 12, 220-231.

12. Hu S, Wang L \& Jiang Z (2017) Dietary additive probiotics modulation of the intestinal microbiota. Protein Peptide Lett 24, 382-387.

13. Patterson JA \& Burkholder KM (2003) Application of prebiotics and probiotics in poultry production. Poult Sci 82, 627-631.

14. Lutful Kabir SM (2009) The role of probiotics in the poultry industry. Int J Mol Sci 10, 3531-3546.

15. Bai K, Huang Q, Zhang J, et al. (2017) Supplemental effects of probiotic Bacillus subtilis fmbJ on growth performance, antioxidant capacity, and meat quality of broiler chickens. Poult Sci 96, 74-82.

16. Rodjan P, Soisuwan K, Thongprajukaew K, et al. (2018) Effect of organic acids or probiotics alone or in combination on growth performance, nutrient digestibility, enzyme activities, intestinal morphology and gut microflora in broiler chickens. J Anim Physiol Anim Nutr 102, e931-e940.

17. Wu Y, Wang B, Zeng Z, et al. (2019) Effects of probiotics Lactobacillus plantarum 16 and Paenibacillus polymyxa 10 on intestinal barrier function, antioxidative capacity, apoptosis, immune response, and biochemical parameters in broilers. Poult Sci 98, 5028-5039.

18. Wang Y, Wang Y, Xu H, et al. (2018) Direct-fed glucose oxidase and its combination with B. amyloliquefaciens SC06 on growth performance, meat quality, intestinal barrier, antioxidative status, and immunity of yellow-feathered broilers. Poult Sci 97, 3540-3549.

19. Sen S, Ingale SL, Kim YW, et al. (2012) Effect of supplementation of Bacillus subtilis LS 1-2 to broiler diets on growth performance, nutrient retention, caecal microbiology and small intestinal morphology. Res Vet Sci $\mathbf{9 3}, 264-268$.

20. Chen W, Wang JP, Yan L, et al. (2013) Evaluation of probiotics in diets with different nutrient densities on growth performance, blood characteristics, relative organ weight and breast meat characteristics in broilers. Br Poult Sci 54, 635-641.

21. Clements LD, Miller BS \& Streips UN (2002) Comparative growth analysis of the facultative anaerobes Bacillus 
subtilis, Bacillus licheniformis, and Escherichia coli. Syst Appl Microbiol 25, 284-286.

22. Neijat M, Shirley R, Welsher A, et al. (2019) Growth performance, apparent retention of components, and excreta dry matter content in Shaver White pullets ( 5 to 16 week of age) in response to dietary supplementation of graded levels of a single strain Bacillus subtilis probiotic. Poult Sci 98, 3777-3786.

23. Mohammadigheisar M, Shirley R, Barton J, et al. (2019) Growth performance and gastrointestinal responses in heavy Tom turkeys fed antibiotic free corn-soybean meal diets supplemented with multiple doses of a single strain Bacillus subtilis probiotic (DSM29784). Poult Sci 98, 5541-5550.

24. Singh AK, Tiwari UP, Berrocoso JD, et al. (2019) Effects of a combination of xylanase, amylase and protease, and probiotics on major nutrients including amino acids and non-starch polysaccharides utilization in broilers fed different level of fibers. Poult Sci $\mathbf{9 8}, 5571-5581$.

25. Kuz'Mina V (1996) Influence of age on digestive enzyme activity in some freshwater teleosts. Aquaculture 148, 25-37.

26. Cowieson AJ, Singh DN \& Adeola O (2006) Prediction of ingredient quality and the effect of a combination of xylanase, amylase, protease and phytase in the diets of broiler chicks. 1. Growth performance and digestible nutrient intake. $\mathrm{Br}$ Poult Sci $\mathbf{4 7}, 477-489$.

27. Owusu-Asiedu A, Simmins P, Brufau J, et al. (2010) Effect of xylanase and $\beta$-glucanase on growth performance and nutrient digestibility in piglets fed wheat-barley-based diets. Livest Sci 134, 76-78.

28. Mathlouthi N, Lalles J, Lepercq P, et al. (2002) Xylanase and $\beta$-glucanase supplementation improve conjugated bile acid fraction in intestinal contents and increase villus size of small intestine wall in broiler chickens fed a rye-based diet. J Anim Sci 80, 2773-2779.

29. Jozefiak D, Rutkowski A, Kaczmarek S, et al. (2010) Effect of $\beta$-glucanase and xylanase supplementation of barley-and rye-based diets on caecal microbiota of broiler chickens. Br Poultry Sci 51, 546-557.

30. Mathlouthi N, Juin H \& Larbier M (2003) Effect of xylanase and $\beta$-glucanase supplementation of wheat-or wheat-and barley-based diets on the performance of male turkeys. Br Poultry Sci 44, 291-298.

31. Adeoye AA, Yomla R, Jaramillo-Torres A, et al. (2016) Combined effects of exogenous enzymes and probiotic on Nile tilapia (Oreochromis niloticus) growth, intestinal morphology and microbiome. Aquaculture $\mathbf{4 6 3}, 61-70$.

32. Nikoskelainen S, Ouwehand AC, Bylund G, et al. (2003) Immune enhancement in rainbow trout (Oncorbynchus mykiss) by potential probiotic bacteria (Lactobacillus rhamnosus). Fish Shellfish Immunol 15, 443-452.

33. Cosson T, Vendrell AMP, Teres BG, et al. (1999) Enzymatic assays for xylanase and $\beta$-glucanase feed enzymes. Anim Feed Sci Tech 77, 345-353.

34. National Research Council (1994) Nutrient Requirements of Poultry, 9th rev. ed. Washington, DC: National Academies Press.

35. Wu Y, Wang B, Zeng Z, et al. (2019) Effects of probiotics Lactobacillus plantarum 16 and Paenibacillus polymyxa 10 on intestinal barrier function, antioxidative capacity, apoptosis, immune response, and biochemical parameters in broilers. Poult Sci 98, 5028-5039.

36. van Es JH, van Gijn ME, Riccio O, et al. (2005) Notch/ $\gamma$-secretase inhibition turns proliferative cells in intestinal crypts and adenomas into goblet cells. Nature 435, 959.

37. Habeebu SSM, Liu J \& Klaassen CD (1998) Cadmium-induced apoptosis in mouse liver. Toxicol Appl Pharm 149, 203-209.
38. Li Y, Wang Y, Wu Y, et al. (2017) Echinacea pupurea extracts promote murine dendritic cell maturation by activation of JNK, p38 MAPK and NF-kB pathways. Dev Comp Immunol 73, 21-26.

39. Geng S, Cheng S, Li Y, et al. (2018) Faecal microbiota transplantation reduces susceptibility to epithelial injury and modulates tryptophan metabolism of the microbial community in a piglet model. J Crohns Colitis 12, 1359-1374.

40. Cao GT, Tao F, Hu YH, et al. (2019) Positive effects of a Clostridium butyricum-based compound probiotic on growth performance, immune responses, intestinal morphology, hypothalamic neurotransmitters, and colonic microbiota in weaned piglets. Food Funct 10, 2926-2934.

41. Cheng G, Hao H, Xie S, et al. (2014) Antibiotic alternatives: the substitution of antibiotics in animal husbandry? Front Microbiol 5, 217.

42. Deng J, Li Y, ZhangJ, et al. (2013) Co-administration of Bacillus subtilis RJGP16 and Lactobacillus salivarius B1 strongly enhances the intestinal mucosal immunity of piglets. Res Vet Sci 94, 62-68.

43. Çınar M, Çatlı A, Küçükyılmaz K, et al. (2009) The effect of single or combined dietary supplementation of prebiotics, organic acid and probiotics on performance and slaughter characteristics of broilers. S Afr J Anim Sci 39, 197-205.

44. Yoo SR, Kim YJ, Park DY, et al. (2013) Probiotics L. plantarum and L. curvatus in combination alter hepatic lipid metabolism and suppress diet-induced obesity. Obesity 21, 2571-2578

45. Rhayat L, Jacquier V, Brinch K, et al. (2017) Bacillus subtilis s train specificity affects performance improvement in broilers. Poult Sci 96, 2274-2280.

46. Tsai T, Dove C, Cline P, et al. (2017) The effect of adding xylanase or $\beta$-glucanase to diets with corn distillers dried grains with solubles (CDDGS) on growth performance and nutrient digestibility in nursery pigs. Livest Sci 197, 46-52.

47. Kelly D, Mulder IE \& Schmidt B (2008) Regulating gut function and immunity. In Formula for the Future: Nutrition or Pathology? Evaluating Performance and Health in Pigs and Poultry, pp. 13-26 [JA Taylor-Pickard, Z Stevenson and K Glebocka, editors]. Wageningen: Wageningen Academic Publishers.

48. Anderson R, Dalziel J, Gopal P, et al. (2012) The Role of Intestinal Barrier Function in Early Life in the Development of Colitis. Croatia: Tech Rijeka.

49. Kelly D \& Conway S (2001) Genomics at work: the global gene response to enteric bacteria. Gut 49, 612-613.

50. Yegani M \& Korver D (2008) Factors affecting intestinal health in poultry. Poult Sci $\mathbf{8 7}, 2052-2063$.

51. Brudnicki A, Brudnicki W, Szymeczko R, et al. (2017) Histo-morphometric adaptation in the small intestine of broiler chicken, after embryonic exposure to $\alpha$-galactosides. J Anim Plant Sci 27, 1075-1082.

52. Al-Fataftah A-R \& Abdelqader A (2014) Effects of dietary Bacillus subtilis on heat-stressed broilers performance, intestinal morphology and microflora composition. Anim Feed Sci Tech 198, 279-285.

53. Johansson ME, Sjövall H \& Hansson GC (2013) The gastrointestinal mucus system in health and disease. Nat Rev Gastro Hepat 10, 352 .

54. Kucharzik T, Walsh SV, Chen J, et al. (2001) Neutrophil transmigration in inflammatory bowel disease is associated with differential expression of epithelial intercellular junction proteins. Am J Pathol 159, 2001-2009.

55. Johansson ME, Larsson JMH \& Hansson GC (2011) The two mucus layers of colon are organized by the MUC2 mucin, 
whereas the outer layer is a legislator of host-microbial interactions. Proc Natl Acad Sci U S A 108, 4659-4665.

56. Van der Sluis M, De Koning BA, De Bruijn AC, et al. (2006) Muc2-deficient mice spontaneously develop colitis, indicating that MUC2 is critical for colonic protection. Gastroenterology 131, $117-129$.

57. Copeland S, Warren HS, Lowry SF, et al. (2005) Acute inflammatory response to endotoxin in mice and humans. Clin Diagn Lab Immun 12, 60-67.

58. Alexander C \& Rietschel ET (2001) Invited review: bacterial lipopolysaccharides and innate immunity. J Endotoxin Res 7, 167-202.

59. Berg RD (1992) Bacterial translocation from the gastrointestinal-tract. J Med 23, 217-244.

60. Melo A, Silveira H, Luciano F, et al. (2016) Intestinal alkaline phosphatase: potential roles in promoting gut health in weanling piglets and its modulation by feed additives - a review. Asian-Australas J Anim Sci 29, 16.

61. Karásková K, Suchý P \& Straková E (2015) Current use of phytogenic feed additives in animal nutrition: a review. Czech J Anim Sci 60, 521-530.

62. Yanbo W \& Zirong X (2006) Effect of probiotics for common carp (Cyprinus carpio) based on growth performance and digestive enzyme activities. Anim Feed Science Tech 127, 283-292.

63. Ogawa A, Kobayashi T, Sakai F, et al. (2015) Lactobacillus gasseri SBT2055 suppresses fatty acid release through enlargement of fat emulsion size in vitro and promotes fecal fat excretion in healthy Japanese subjects. Lipids Health Dis 14, 20.

64. Bai K, Huang Q, Zhang J, et al. (2016) Supplemental effects of probiotic Bacillus subtilis fmbJ on growth performance, antioxidant capacity, and meat quality of broiler chickens. Poult Sci 96, 74-82.

65. Salami SA, Majoka MA, Saha S, et al. (2015) Efficacy of dietary antioxidants on broiler oxidative stress, performance and meat quality: science and market. Avian Biol Res 8, 65-78.

66. Surai PF (2016) Antioxidant systems in poultry biology: superoxide dismutase. J Anim Res Nutr $\mathbf{1}, 8$.

67. Zhu LH, Zhao KL, Chen XL, et al. (2012) Impact of weaning and an antioxidant blend on intestinal barrier function and antioxidant status in pigs. J Anim Sci $\mathbf{9 0}, 2581-2589$.

68. Sies H, Stahl W \& Sevanian A (2005) Nutritional, dietary and postprandial oxidative stress. J Nutr 135, 969-972.

69. Amaretti A, Di Nunzio M, Pompei A, et al. (2013) Antioxidant properties of potentially probiotic bacteria: in vitro and in vivo activities. Appl Microbiol Biot 97, 809-817.

70. Hu Y, Wang Y, Li A, et al. (2016) Effects of fermented rapeseed meal on antioxidant functions, serum biochemical parameters and intestinal morphology in broilers. Food Agric Immunol 27, 182-193.

71. Bauché F, Fouchard M-H \& Jégou B (1994) Antioxidant system in rat testicular cells. FEBS Lett 349, 392-396.

72. Delles RM, Xiong YL, True AD, et al. (2014) Dietary antioxidant supplementation enhances lipid and protein oxidative stability of chicken broiler meat through promotion of antioxidant enzyme activity. Poult Sci 93, 1561-1570.

73. Higuchi BS, Rodrigues N, Gonzaga MI, et al. (2018) Intestinal dysbiosis in autoimmune diabetes is correlated with poor glycemic control and increased interleukin-6: a pilot study. Front Immunol 9, 1689.

74. Shaw AC, Joshi S, Greenwood H, et al. (2010) Aging of the innate immune system. Curr Opin Immunol 22, 507-513.

75. Wilson D, Jackson T, Sapey E, et al. (2017) Frailty and sarcopenia: the potential role of an aged immune system. Ageing Res Rev 36, 1-10.

76. Förstermann U \& Sessa WC (2011) Nitric oxide synthases: regulation and function. Eur Heart J 33, 829-837.

77. Bakker-Zierikzee A, Van Tol E, Kroes H, et al. (2006) Faecal SIgA secretion in infants fed on pre- or probiotic infant formula. Pediat Allergy Imm 17, 134-140.

78. Brandtzaeg P (2003) Role of secretory antibodies in the defence against infections. Int J Med Microbiol 293, 3-15.

79. Neish AS (2009) Microbes in gastrointestinal health and disease. Gastroenterology 136, 65-80.

80. Kristensen NB, Bryrup T, Allin KH, et al. (2016) Alterations in fecal microbiota composition by probiotic supplementation in healthy adults: a systematic review of randomized controlled trials. Genome Med 8, 52 .

81. Lei X, Piao X, Ru Y, et al. (2015) Effect of Bacillus amyloliquefaciens-based direct-fed microbial on performance, nutrient utilization, intestinal morphology and cecal microflora in broiler chickens. Asian-Australas J Anim Sci 28, 239.

82. Mountzouris K, Tsitrsikos P, Palamidi I, et al. (2010) Effects of probiotic inclusion levels in broiler nutrition on growth performance, nutrient digestibility, plasma immunoglobulins, and cecal microflora composition. Poult Sci 89, 58-67.

83. Mountzouris K, Tsirtsikos P, Kalamara E, et al. (2007) Evaluation of the efficacy of a probiotic containing Lactobacillus, Bifidobacterium, Enterococcus, and Pediococcus strains in promoting broiler performance and modulating cecal microflora composition and metabolic activities. Poult Sci 86, 309-317.

84. Yang C, Cao G, Ferket P, et al. (2012) Effects of probiotic, Clostridium butyricum, on growth performance, immune function, and cecal microflora in broiler chickens. Poult Sci 91, 2121-2129.

85. Hu L, Geng S, Li Y, et al. (2018) Exogenous fecal microbiota transplantation from local adult pigs to crossbred newborn piglets. Front Microbiol 8, 2663.

86. Gophna U, Konikoff $\mathrm{T}$ \& Nielsen HB (2017) Oscillospira and related bacteria - from metagenomic species to metabolic features. Environ Microbiol 19, 835-841.

87. Turnbaugh PJ, Ley RE, Mahowald MA, et al. (2006) An obesityassociated gut microbiome with increased capacity for energy harvest. Nature 444, 1027.

88. Shin N-R, Whon TW \& Bae J-W (2015) Proteobacteria: microbial signature of dysbiosis in gut microbiota. Trends Biotechnol $\mathbf{3 3}$, 496-503.

89. Kamada N, Kim Y-G, Sham HP, et al. (2012) Regulated virulence controls the ability of a pathogen to compete with the gut microbiota. Science 336, 1325-1329. 